Ambiente \& Água - An Interdisciplinary Journal of Applied Science
ISSN 1980-993X - doi:10.4136/1980-993X
www.ambi-agua.net
E-mail: ambi-agua@agro.unitau.br

\title{
Caracterização de ambientes aquáticos no rio de Ondas, cerrado baiano
}

\author{
doi: 10.4136/ambi-agua.1535
}

Received: 20 Oct. 2014; Accepted: 21 Nov. 2014

\author{
Elis Regina Rodrigues de Souza Castro ${ }^{1 *}$; Michel Castro Moreira ${ }^{2}$; \\ Luís Gomes Carvalho ${ }^{2}$; Demetrius David da Silva ${ }^{3}$

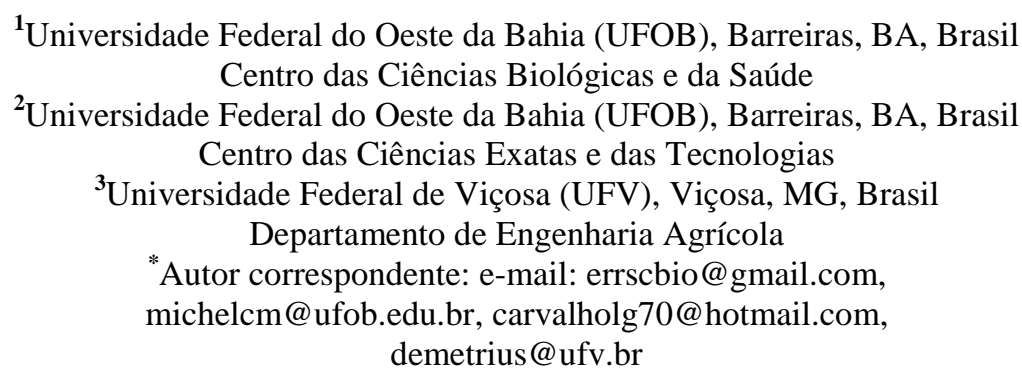

\section{RESUMO}

O objetivo do presente trabalho foi realizar a caracterização da disponibilidade dos ambientes aquáticos presentes no rio de Ondas, visando obter informações sobre a complexidade estrutural e subsídiar políticas públicas de gestão dos recursos hídricos que permitam o uso compartilhado da água e a proteção da biodiversidade da bacia. O rio de Ondas drena área de $5.559 \mathrm{~km}^{2}$, localizada no oeste baiano, em uma região de cerrado. Para a caracterização, foram delimitados dois trechos: no alto e no baixo curso da bacia, onde foram realizados um levantamento topobatimétrico, caracterização do leito e hidráulica nos períodos seco e chuvoso. No levantamento topobatimétrico, verificou-se que no alto curso, as altitudes variaram de $699,82 \mathrm{~m}$ a $714,06 \mathrm{~m}$ e no baixo curso de 439,45 m a 446,91 m. Os perfis batimétricos permitiram a visualização da estrutura do leito e da distribuição dos ambientes no canal. Na análise granulométrica do alto curso predominou areia $(88,94 \%)$, enquanto no baixo curso matacão $(76,9 \%)$ e blocos $(23,1 \%)$. No alto curso, a vazão variou de $5,20 \mathrm{~m}^{3} \mathrm{~s}^{-1}$ (seco) a $9,07 \mathrm{~m}^{3} \mathrm{~s}^{-1}$ (chuvoso); e no baixo curso de $25,73 \mathrm{~m}^{3} \mathrm{~s}^{-1}$ (seco) a $66,44 \mathrm{~m}^{3} \mathrm{~s}^{-1}$ (chuvoso). A complexidade dos ambientes dos trechos favorece a diversidade biológica no rio de Ondas, resultando na disponibilidade de ambientes com diferentes características que beneficiam as aptidões das espécies aquáticas à estrutura do canal. $\mathrm{O}$ estudo das características físicas do rio de Ondas possibilitou um amplo conhecimento dos micro-ambientes nos trechos estudados, subsidiando estudos relativos à biota aquática e à gestão de recursos hídricos.

Palavras-chave: ADCP, biota aquática, granulometria, topobatimetria. 


\title{
Characterization of aquatic environments in the De Ondas River, Bahian Cerrado
}

\begin{abstract}
This work sought to characterize the types of environments present in the De Ondas River, with the aim of obtaining information on their structural complexity and supporting public policies for water resource management that will allow the shared water use and will protect the biodiversity of the river basin. The De Ondas River watershed is located in the Cerrado Region, in the western part of Bahia State, and covers an area of $5.559 \mathrm{~km}^{2}$. In order to perform the characterization, two stretches were demarcated, one in the upper part of the basin and another in the lower. Afterwards, a topobathymetric survey was conducted, and characterizations of the bottom and of hydraulic properties were done for both the rainy and dry seasons. The topobathymetric survey in the upper course showed altitudes ranging from $699.82 \mathrm{~m}$ to 714.06 , whereas in the lower course these varied from $439.45 \mathrm{~m}$ to $446.91 \mathrm{~m}$. Bathymetric profiles allowed the visualization of the structure and distribution of the bottom of the channel environments. The granulometric analysis of the higher part of the basin showed that sand was predominant $(88.94 \%)$, while in the lower part boulders $(76.9 \%)$ and cobble $(23.1 \%)$ predominated. In the higher part of the basin, the water flow varied from $5.20 \mathrm{~m}^{3} \mathrm{~s}^{-1}$ (dry period) to $9.07 \mathrm{~m}^{3} \mathrm{~s}^{-1}$ (rainy period); and in the lower part, from $25.73 \mathrm{~m}^{3} \mathrm{~s}^{-1}$ (dry period) to $66.44 \mathrm{~m}^{3} \mathrm{~s}^{-1}$ (rainy period). The complexity of the environments of these stretches favors biological diversity in the river, resulting in different environments that aid aquatic species in adapting to the channel structure. The study of the physical characteristics of the De Ondas River produced a great amount of information regarding the microenvironments of the stretches examined, and will support studies related to aquatic biota and water resource management.
\end{abstract}

Keywords: ADCP, aquatic biota, granulometry, topobathymetry.

\section{INTRODUÇÃO}

O estudo das características ecológicas de um rio se configura como a melhor maneira de compreender quais fatores interferem na biodiversidade aquática, possibilitando a compreensão da estrutura do ambiente aquático (Ferreira e Castro, 2005). O estudo da estrutura do ambiente aquático corresponde à análise das alterações geológicas, vegetacionais, climáticas e topográficas, as quais associadas e ao longo do tempo, contribuem para a evolução da paisagem de um rio (Beschta e Platts, 1986).

Os fatores abióticos agem sobre as espécies, servindo como um filtro que determina, a princípio, a abundância de indivíduos em um local com determinadas características. Fundamentando-se em tais aspectos, pode-se afirmar que uma maior complexidade física do ambiente promoverá um aumento da riqueza de espécies, devido à maior disponibilidade e combinações de ambientes correlacionados com as aptidões das espécies (Allan e Castillo, 2007).

Fundamentando-se nas relações entre a biota aquática e o ambiente físico do rio, Vannote et al. (1980) propuseram a Teoria do Rio Continuum. Esta teoria considera os rios como sendo sistemas que possuem gradientes contínuos de características físicas ao longo de seus cursos, que resultaram nas adaptações evolutivas das espécies aquáticas. Uma extensão desta teoria foi postulada por Ward e Stanford (1983), que previram a descontinuidade serial resultante da ação antrópica ao longo do gradiente longitudinal da bacia. Nesta descontinuidade, consideraram que as interferências ao longo do contínuo fluvial irão definir as modificações no gradiente das características físicas e da biota aquática do rio. 
A estrutura do ambiente aquático está associada aos componentes do canal, como o material presente no leito (Boëchat et al., 2013; Hawkins et al., 1993); sua morfologia, representada pelas características do leito, como a profundidade, a largura e a forma do canal; e o estudo de parâmetros hidráulicos, que possuem grande importância na descrição de ambientes (Jowett, 1993).

Dentre os diversos parâmetros utilizados na caracterização da estrutura do ambiente, destaca-se o estudo do material presente no leito do rio. Realizada através da análise granulométrica, a caracterização do material do leito constitui em importante indicador da capacidade de transporte dos canais, dos ambientes deposicionais e, principalmente, das mudanças ocorridas na dinâmica e morfologia fluvial (Leandro e Souza, 2012). Além disso, a caracterização do leito fornece informações sobre as interações entre os parâmetros limnológicos e bióticos nos ecossistemas aquáticos, correspondendo a um dos fatores responsáveis pela distribuição das comunidades aquáticas (Queiroz e Rocha, 2010; Rodrigues et al., 2010).

Melhor entendimento da configuração dos ambientes aquáticos é dado pelo estudo da morfologia do canal, feito através do levantamento da topografia do leito (Jowett, 1993), que possibilita o conhecimento de suas características morfométricas por meio da representação do leito por perfis batimétricos, os quais são gerados por georreferenciamento da superfície d'água e pelas medições das profundidades do canal (Krueger et al., 2003; Resck et al., 2007). Os levantamentos topobatimétricos, subsidiam estudos relacionados com a ecologia dos organismos aquático, tornando-se essencial no estabelecimento de planos de gestão sustentável dos ecossistemas aquáticos (Bezerra-Neto e Pinto-Coelho, 2008).

As características hidráulicas descrevem também muitos dos parâmetros relacionados à estrutura do ambiente, pois permitem estimar a dimensão da bacia, os tipos de escoamentos, além de subsidiar a criação de modelos que as representem. Modificações nessas características interferem decisivamente no escoamento, na qualidade da água e, consequentemente, na biota aquática. Dessa forma, o estudo das condições hidráulicas dos rios é essencial para a verificação das suas condições ambientais (Martins e Honda, 2004).

Rodrigues et al. (2010) destacam a importância dos estudos da estrutura dos ambientes para a conservação e o gerenciamento dos recursos hídricos, os quais fornecem dados que possibilitam avaliar os níveis de impactos antrópicos nas bacias hidrográficas. Além disso, os rios são ecossistemas abertos, com elevada conectividade longitudinal, lateral e vertical (Allan e Castillo, 2007), que estão sempre recebendo pressões externas, comprometedoras da sua qualidade (Barbour et al., 1999).

$\mathrm{Na}$ bacia do rio de Ondas, localizada no oeste do Estado da Bahia e caracterizada pelo bioma cerrado, verifica-se acelerado crescimento econômico advindo da agricultura irrigada. Devido ao intenso uso da água, podem ter ocorrido perdas ambientais relacionadas à disponibilidade hídrica e ao ecossistema aquático, tendo em vista a demanda dos recursos hídricos sem um gerenciamento integrado que vise à conservação da integridade das espécies aquáticas.

Além da constatação do intenso uso da água, na região é evidenciada grande carência de trabalhos que contemplem suas características ambientais. A falta dessas informações indica a necessidade de estudos que subsidiem políticas que contemplem as particularidades locais. Deste modo, o objetivo do presente trabalho foi realizar a caracterização da disponibilidade dos ambientes aquáticos presentes no rio de Ondas, visando obter informações sobre a sua complexidade estrutural e subsidiar políticas públicas de gestão dos recursos hídricos que permitam o uso compartilhado da água e a proteção da biodiversidade aquática da bacia. 


\section{MATERIAL E MÉTODOS}

\section{1. Área de estudo}

A bacia hidrográfica do rio de Ondas, localizada nos municípios de Barreiras e Luís Eduardo Magalhães, região oeste do Estado da Bahia, possui área de aproximadamente $5.559 \mathrm{~km}^{2}$ (Figura 1). O rio de Ondas apresenta comprimento de $144 \mathrm{~km}$, altitude variando de $900 \mathrm{~m}$ a $400 \mathrm{~m}$, e possui como principais tributários os rios das Pedras, Borá e riacho Cabeceira das Lajes (Damasceno, 2011; Soares Neto e Souza, 2007).

Visando realizar a caracterização da disponibilidade dos ambientes aquáticos no rio de Ondas, foram selecionados dois trechos de 300 m de extensão, distantes entre si em $100 \mathrm{~km}$, com condições ambientais distintas, sendo um localizado no alto curso e outro no baixo curso da bacia (Figura 1).
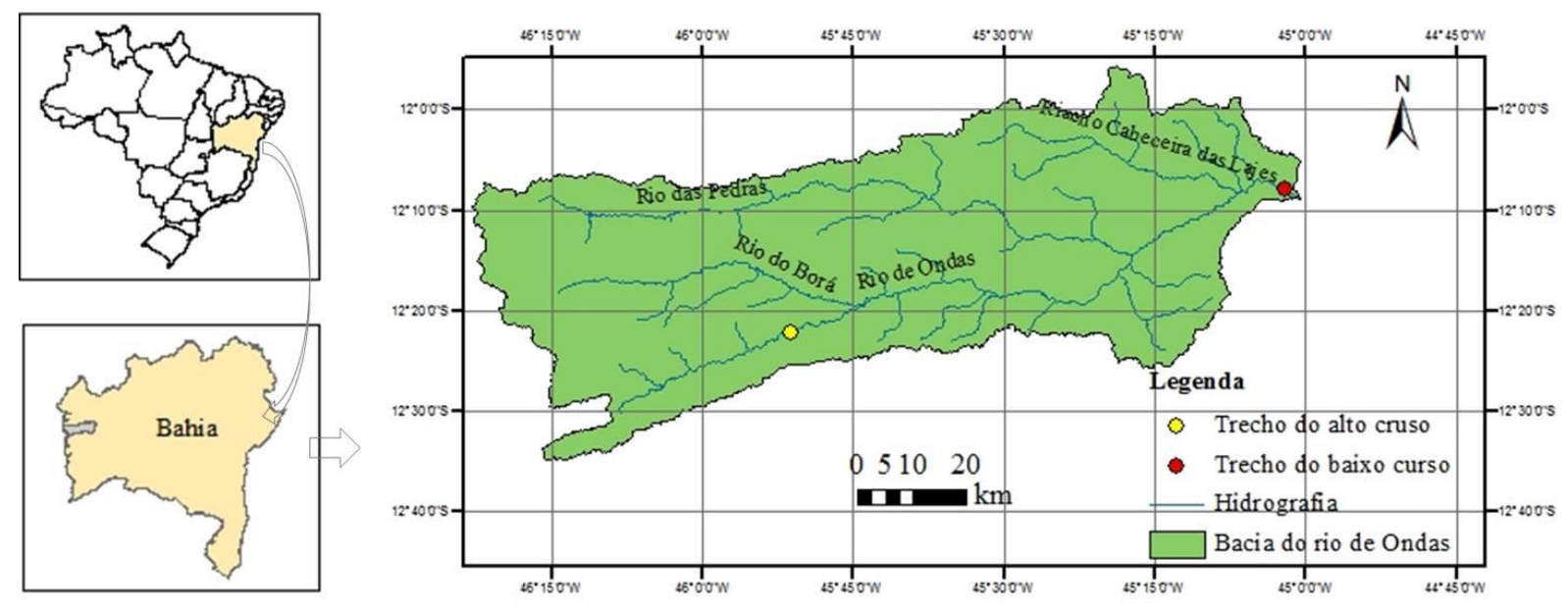

Figura 1. Localização da bacia do rio de Ondas e dos trechos de estudo.

\subsection{Coleta de dados}

Para caracterização dos ambientes aquáticos dos trechos do rio de Ondas, foram realizadas as seguintes atividades: levantamento topobatimétrico; caracterização do material do leito; e caracterização hidráulica.

\subsubsection{Levantamento topobatimétrico}

O levantamento topográfico das margens dos trechos foi realizado utilizando-se GPS Geodésico (Leica, modelo ATX900), contendo dois receptores geodésicos de dupla frequência L1/L2, conforme metodologia proposta pelo IBGE (2009); e uma estação total (Nikon, modelo DT332) com dois prismas.

Os dados obtidos pelo GPS Geodésico foram processados no programa computacional Leica GeoOffice, enquanto os dados levantados pela estação total foram processados no programa computacional GeoOffice Topográfico Profissional.

A batimetria no trecho do alto curso do rio de Ondas foi realizada com a utilização do Acoustic Doppler Current Profiler (ADCP) (Sontek, modelo M9) composto de dois conjuntos de transdutores para medições de velocidade, um feixe acústico vertical de $0,50 \mathrm{MHz}$ para medição da profundidade e um sistema de GPS e RTK acoplado para determinação do posicionamento dos equipamentos (Sontek, 2009).

No levantamento com o ADCP, as linhas batimétricas foram definidas em zigue-zague por toda a área do trecho (Bezerra-Neto e Pinto-Coelho, 2008), sendo um condutor colocado em cada margem para guiar o deslocamento do equipamento. 
Os dados coletados foram processados utilizando-se o programa computacional SonTek RiverSurveyor Live, sendo posteriormente exportados e editados na planilha no Microsoft Excel para pós-processamento no programa computacional ESRI ArcGis $10^{\circledR}$.

No trecho do baixo curso do rio de Ondas, devido à elevada quantidade de material grosseiro, o levantamento batimétrico foi realizado com a utilização de estação total e bastão de altura fixa de $2 \mathrm{~m}$ com prisma. Os pontos de apoio e de distribuição das linhas batimétricas foram materializados através dos marcos de concreto instalados nas seções transversais. Realizou-se o levantamento concentrando a coleta nas áreas onde ocorreram mudanças na topografia do leito do canal.

\subsubsection{Caracterização hidráulica}

Para a medição dos parâmetros hidráulicos dos trechos foi utilizado o ADCP. As medições foram realizadas durante os períodos seco e chuvoso, característicos da região, em três seções transversais em cada trecho delimitadas para este procedimento. Em cada seção transversal foram realizadas oito medições dos parâmetros, correspondendo à profundidade $(\mathrm{m})$, à largura $(\mathrm{m})$, à velocidade $\left(\mathrm{m} \mathrm{s}^{-1}\right)$ e à vazão $\left(\mathrm{m}^{3} \mathrm{~s}^{-1}\right)$.

A análise do desvio padrão e do coeficiente de variação dos parâmetros obtidos pelo ADCP foi realizada no programa SonTek RiverSurveyor, sendo aceitas as leituras que apresentassem um coeficiente de variação de até 5\% (Sontek, 2009). Os valores dos parâmetros foram obtidos a partir das médias referentes às oito medições.

\subsubsection{Caracterização do leito}

Devido à heterogeneidade das partículas distribuídas nos trechos de estudo, a caracterização do leito do canal foi realizada empregando-se diferentes técnicas. Em locais que apresentavam partículas de menor diâmetro, como areia e seixo, foram coletadas 18 amostras ao longo de cada trecho do material de fundo com amostrador de arrasto. As amostras foram armazenadas em sacos plásticos identificados por trecho e ponto de coleta e transportadas para o Laboratório de Engenharia Civil da Universidade Federal do Oeste da Bahia.

A preparação das amostras baseou-se nas metodologias propostas pela NBR 6457/86 (ABNT, 1986) e NBR 7181/84 (ABNT, 1984). Para separação das frações de argila, silte e areia, foi utilizado o método de pipetagem (EMBRAPA, 1997), e para separação das frações grosseiras foi utilizado o método do peneiramento (ABNT, 1986). Além disso, para a determinação da umidade e do fator de correção das amostras, foram utilizados os procedimentos propostos pela EMBRAPA (1997).

No trecho do baixo curso, onde há predominância de partículas grosseiras, estas foram coletadas para realização de medições dos seus eixos, visando à obtenção do diâmetro médio, conforme a técnica de medição e cálculo do diâmetro médio das partículas (Cunha e Guerra, 2011). Nesta análise foi utilizada a classificação granulométrica proposta por Wentworth (1922).

\subsection{Análise da disponibilidade de ambientes para os organismos aquáticos}

A análise da disponibilidade de ambientes aquáticos foi realizada a partir da correlação da topobatimetria com os parâmetros hidrodinâmicos (vazão, profundidade e velocidade do escoamento), da granulometria do material do leito, e a vegetação superficial e aquática encontrados nos trechos do rio de Ondas.

A caracterização dos ambientes deu-se a partir da análise das diferentes características ambientais de cada trecho e de suas alterações ao longo dos períodos sazonais. Observaram-se, também, a estruturação, a distribuição e a abundância da condição do ambiente imposta através da associação dos parâmetros, que correspondem a uma fonte potencial de limitação para a biota aquática (Barbour et al., 1999). 


\section{RESULTADOS E DISCUSSÃO}

\subsection{Levantamento topobatimétrico}

Na Figura 2 apresenta-se a distribuição dos pontos levantados, bem como a superfície batimétrica de montante a jusante vista em 3D do trecho do alto curso. Neste trecho foram levantados 1.550 pontos, com altitudes variando entre $699,82 \mathrm{~m}$ e 714,06 m. Na Figura 2 verifica-se menor concentração de pontos coletados na margem esquerda, fato associado à extensa mata de galeria inundável, que dificultou o acesso e a realização de um estudo mais detalhado dessa margem.

Pela análise da Figura 2, verifica-se na superfície batimétrica em 3D que o canal deste trecho possui uma distribuição descontínua das profundidades, entre locais rasos e profundos, sendo que os pontos mais profundos do trecho localizam-se próximos à região mais a jusante do canal.

Pode-se verificar também a presença de ambientes de erosão e sedimentação localizados principalmente na margem direita do canal, na qual ocorrem áreas com topografia irregular ao longo do trecho, como mostrado na superfície 3D (Figura 2). Na margem esquerda, de forma contrária, observa-se que o canal é mais profundo em relação à margem direita.
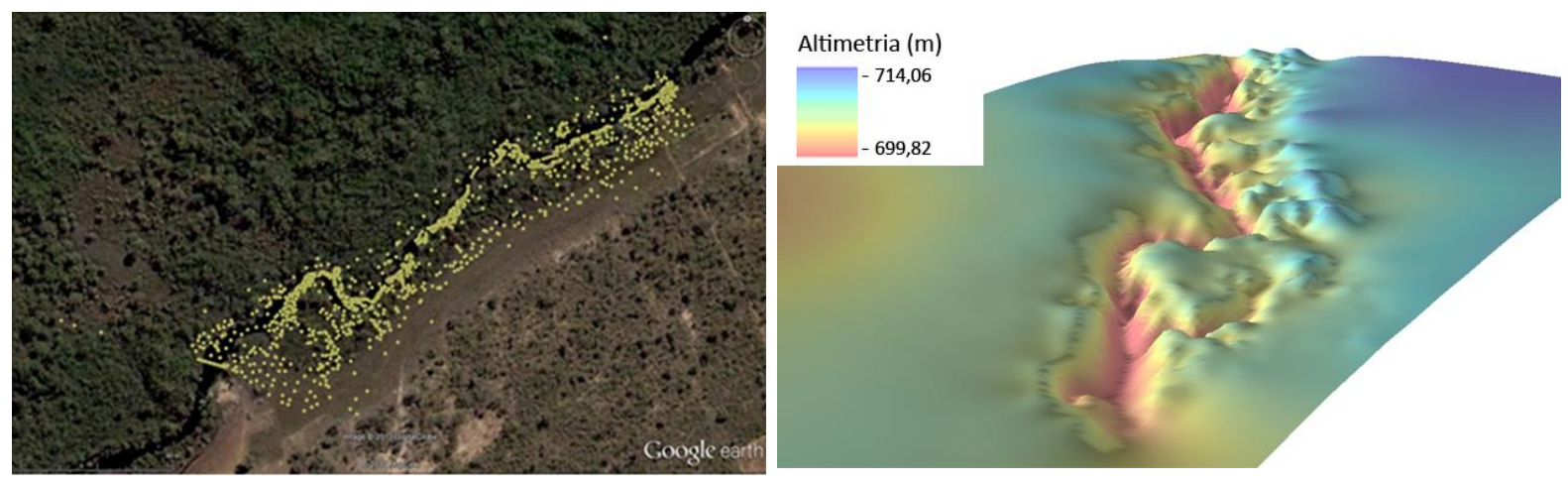

Figura 2. Distribuição dos pontos do levantamento batimétrico no trecho do alto curso do rio de Ondas e vista em 3D da superfície batimétrica de montante para jusante.

Fonte: Adaptado de Google Earth (2013).

Na Figura 3 apresenta-se a distribuição dos pontos levantados no trecho do baixo curso, bem como sua superfície batimétrica de montante a jusante em 3D. Neste trecho foram levantados 1.326 pontos, com altitude variando de $439,45 \mathrm{~m}$ a $446,91 \mathrm{~m}$. Pela análise da Figura 3, percebe-se que os pontos foram levantados de forma distribuída em todo o trecho. Em alguns locais, notadamente os mais profundos e turbulentos, devido à dificuldade de se fixar o bastão para a leitura da altitude, há menor concentração de pontos em relação às demais áreas.

Os resultados do levantamento topobatimétrico do baixo rio de Ondas demostraram o detalhamento da superfície batimétrica, advinda principalmente da extensa malha amostral. $\mathrm{Na}$ representação da superfície do canal, percebe-se que as maiores profundidades ocorrem na região à jusante do trecho, em local que se verifica um estreitamento do canal. Além disso, pode-se constatar que o leito é mais regular no início do trecho, sendo que para jusante aumentam-se as irregularidades no leito, ocorrendo zonas descontínuas com altas variações na profundidade.

Essas variações nos perfis mostram a diversidade na disponibilidade de ambiente nesse trecho, com depressões próximas às margens, formando remansos, e corredeiras nos locais mais profundos no centro do canal, podendo contribuir também para a diversidade dos organismos aquáticos, como explicado por Jowett (1993). 

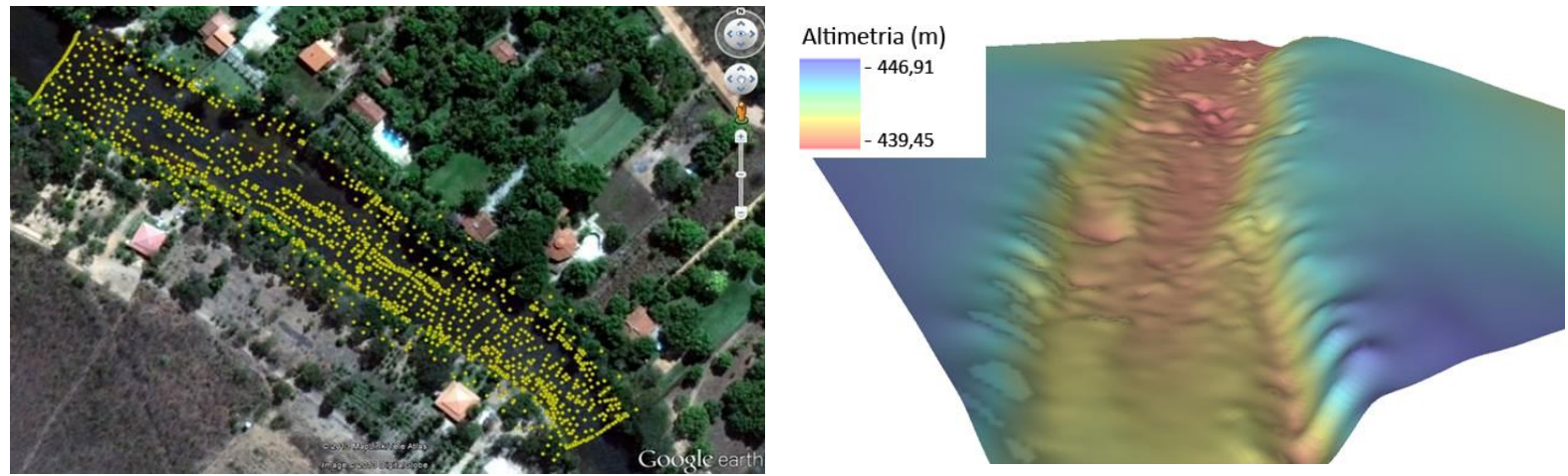

Figura 3. Distribuição dos pontos do levantamento batimétrico no trecho do baixo curso do rio de Ondas e vista em 3D da superfície batimétrica de montante para jusante.

Fonte: Adaptado de Google Earth (2013).

Os perfis batimétricos gerados para os dois trechos estudados no rio de Ondas permitiram a visualização da estrutura do leito e, principalmente, da distribuição dos diferentes ambientes, corredeiras e remansos no canal, confirmando as observações de Resck et al. (2007), que afirmam que os levantamentos batimétricos permitem a definição e visualização das características morfométricas do canal e melhor entendimento da estrutura e do funcionamento dos ecossistemas aquáticos.

Analisando os dois trechos de estudo do rio de Ondas, pode-se constatar que no trecho do alto curso o canal apresenta-se com margens vegetadas e predominância de leito arenoso, observando-se uma migração/erosão lateral na área, devido principalmente ao fato de o rio não possuir mais espaço e capacidade para erodir verticalmente o leito. No trecho do baixo curso, observa-se predominância de material grosseiro, elevada declividade, pouca vegetação em suas margens, e elevada energia que possibilita a erosão vertical do leito.

\subsection{Caracterização hidráulica}

Os parâmetros hidráulicos relacionados às características geométricas do trecho do alto curso estão descritos na Tabela 1.

Tabela 1. Dados médios dos parâmetros hidráulicos do trecho do alto curso do rio de Ondas durante os períodos sazonais.

\begin{tabular}{lcccc}
\hline Período & $\begin{array}{c}\text { Largura } \\
(\mathbf{m})\end{array}$ & $\begin{array}{c}\text { Profundidade } \\
\text { média }(\mathbf{m})\end{array}$ & $\begin{array}{c}\text { Velocidade } \\
\text { média }\left(\mathbf{m ~ s}^{-1}\right)\end{array}$ & $\begin{array}{c}\text { Vazão } \\
\left(\mathbf{m}^{\mathbf{3}} \mathbf{~ s}^{-1}\right)\end{array}$ \\
\hline Seco & 6,87 & 2,22 & 0,37 & 5,20 \\
Chuvoso & 19,92 & 1,50 & 0,32 & 9,07 \\
\hline
\end{tabular}

O fato do canal do trecho do alto curso possuir sinuosidades formando áreas de depressões e corredeiras, e de localizar-se em região com ambiente preservado, com amplo sistema radicular da vegetação das margens que proporciona maior estabilidade dos solos, pode ter auxiliado na estabilização da geometria hidráulica das seções durante o período de estudo. Isso pode ser constatado pelo decréscimo da velocidade média verificada a jusante, concluindo-se que a presença de galhos submersos no leito favoreceu o retardamento do escoamento superficial e do fluxo do canal, como evidenciado por Oliveira (2011) ao estudar a geometria hidráulica dos canais fluviais da bacia do rio Cascavel no Paraná.

Neste trecho, verificou-se que durante o período chuvoso há um elevado transbordamento do canal para a planície de inundação, mudando a configuração do leito. Nesses casos, as maiores profundidades ocorrem no talvegue, com pequenas variações da 
profundidade na planície de inundação, o que influencia os valores das profundidades médias das seções transversais, que são maiores durante o período seco em relação ao período chuvoso (Tabela 1).

Além disso, este transbordamento do canal provoca mudanças previsíveis no ambiente aquático interferindo na sua biota. Tal situação foi constatada por Tejerina-Garro e Mérona (2010) e Goldstein et al. (2007), que encontraram grandes diferenças nas assembleias de peixes relacionadas a oscilações da vazão, evidenciando que este é o principal fator que controla a comunidade ictiofaunística. Devido a este fato, os organismos aquáticos desse trecho podem encontrar-se também mais vulneráveis às atividades antrópicas de degradação dessas planícies.

No período chuvoso, as profundidades dentro do canal foram mais elevadas, possuindo profundidade máxima de $5,46 \mathrm{~m}$. No período seco, em que a vazão ficou concentrada no canal, sem transbordamento para a planície de inundação, a maior profundidade encontrada foi de $4,44 \mathrm{~m}$.

As características hidráulicas mensuradas no trecho do baixo curso do rio de Ondas estão apresentadas na Tabela 2.

Os resultados do estudo no trecho do baixo curso confirmaram a característica de um canal encaixado, com pouco transbordamento das margens e considerável elevação nas profundidades durante o período chuvoso. Neste trecho, durante o período chuvoso, a profundidade máxima observada foi de $1,86 \mathrm{~m}$, contrastando-se com o período seco, que esta profundidade apresentou valores de $1,52 \mathrm{~m}$.

Tabela 2. Dados médios dos parâmetros hidráulicos do trecho do baixo curso do rio de Ondas durante os períodos sazonais.

\begin{tabular}{lcccc}
\hline Período & $\begin{array}{c}\text { Largura } \\
(\mathbf{m})\end{array}$ & $\begin{array}{c}\text { Profundidade } \\
\text { média }(\mathbf{m})\end{array}$ & $\begin{array}{c}\text { Velocidade } \\
\text { média }\left(\mathbf{m ~ s}^{-1}\right)\end{array}$ & $\begin{array}{c}\text { Vazão } \\
\left(\mathbf{m}^{\mathbf{3}} \mathbf{s}^{-1}\right)\end{array}$ \\
\hline Seco & 41,64 & 0,76 & 0,83 & 25,73 \\
Chuvoso & 46,47 & 1,06 & 1,39 & 66,44 \\
\hline
\end{tabular}

Pesquisas mostram que somente o estudo da velocidade e da profundidade não são significativos para elencar modificações nas comunidades aquáticas, sendo necessária a incorporação dos dados da vazão que influenciam decisivamente nessas comunidades (Cortes et al., 2008; Gorman e Kar, 1978; Kaufmann e Pinheiro, 2009; Tupinambás et al., 2011). Mesmo com tais afirmações, Marsh-Matthews e Matthews (2000) e Vlach et al. (2005) encontraram relação direta entre o aumento da profundidade e velocidade do canal com o aumento da diversidade de peixes.

A elevada flutuação sazonal na vazão, que se pode verificar nos dois trechos do rio de Ondas, resulta em alterações longitudinais e laterais do escoamento, que contribuem decisivamente para uma variada dinâmica das espécies aquáticas (Kaufmann e Pinheiro, 2009). Dentre as espécies da comunidade aquática, os peixes apresentam destaque pela necessidade desta variabilidade sazonal da vazão, que é fundamental na realização de suas diversas funções vitais (Lowe-McConnell, 1999).

Fantin-Cruz et al. (2008) afirmam que as variações espaciais e temporais das comunidades aquáticas respondem tanto à variação da vazão quanto às características morfométricas dos canais, refletindo nos diferentes comportamentos hidrodinâmicos dos trechos estudados no rio de Ondas, devido principalmente a descontinuidade serial resultante das variações litológicas ao longo do gradiente longitudinal deste rio. Dessa forma, considerando os aspectos estruturais do rio de Ondas, não é adequada a aplicação da Teoria 
do Rio Continuum, pois no alto curso do rio verifica-se uma energia hidráulica inferior à observada no baixo curso.

\subsection{Caracterização do leito}

As características ambientais diferenciadas dos trechos refletiram na composição granulométrica do leito do canal. Os resultados da análise granulométrica do trecho do alto curso mostraram predominância de textura arenosa $(88,94 \%)$, sendo ainda verificados seixos $(7,2 \%)$, argila $(3,5 \%)$ e silte $(0,35 \%)$.

As características granulométricas ocorrentes neste trecho estão associadas aos tipos de solos presentes na região, sendo eles o Neossolo Quartzarênico e o Gleissolo. O primeiro apresenta textura predominante de areia e o segundo tem essa textura principalmente nos horizontes superficiais (EMBRAPA, 2009), conforme constatado por Soares Neto (2005) e Castro et al. (2010) em estudos realizados no alto rio de Ondas.

No trecho do baixo curso, verificam-se a predominância de partículas com diâmetros grosseiros e com diferentes tamanhos e deposição de areia, com intercalações de materiais grosseiros próximos às margens.

Os resultados do método de medição do diâmetro médio das partículas mostraram a predominância de matacão $(76,9 \%)$ e bloco $(23,1 \%)$ neste trecho. Nos ambientes deposicionais marginais, nos quais foram verificadas associações entre areia e seixos, devido à impossibilidade de utilização do método do diâmetro médio das partículas, as amostras foram analisadas por pipetagem e peneiramento, obtendo como resultado os valores de $50,1 \%$ de areia, $46,7 \%$ de seixos, $2,5 \%$ de argila e $0,75 \%$ de silte.

Os resultados mostraram que a composição granulométrica desse trecho pode ser explicada principalmente pela litologia da região, associado à elevada velocidade do escoamento que auxilia no processo de erosão da rocha. Os solos nessa região são basicamente Neossolos Litólicos e Argissolos Vermelhos-Amarelos (Soares Neto e Souza, 2007). Os Neossolos Litólicos tem $90 \%$ ou mais de sua massa constituída por fragmentos de rocha com diâmetros maiores que $2 \mathrm{~mm}$, com predominância de cascalhos, calhaus e matacões (EMBRAPA, 2009).

A deposição de areia em alguns pontos das margens justifica-se pela diminuição da velocidade do escoamento, que propicia sua deposição nos bancos vegetados na área durante o período seco. Pode-se constatar, no entanto, que nessas áreas ocorrem intercalações entre areia e seixo, confirmando a elevada ocorrência de partículas com composição granulométrica grosseira.

Allan e Castillo (2007) apontam o material do leito como um componente crítico do ambiente aquático, principalmente por sofrer influência direta do ciclo hidrológico. Além disso, muitas espécies aquáticas possuem afinidade para determinada classe de diâmetro do material presente no leito (Souza e Barrella, 2009).

Dentre as preferências apresentadas pelos organismos aquáticos, há maior frequência para escolha de ambientes que possuem materiais com diâmetros elevados (Boëchat et al., 2013). Na maioria das vezes, eles se encontram com uma fauna mais diversificada, quando comparados com ambientes com materiais de granulometria fina (Barbour et al., 1999; Boëchat et al., 2013; Gordon et al., 2004; Minatti-Ferreira e Beaumord, 2006; Rodrigues et al., 2010).

Dessa forma, considerando a textura do material do leito, o trecho do baixo curso possui vantagens estruturais sobre o trecho do alto curso. Por sua vez, no alto curso predominam outras estruturas estratégicas do leito, como tocas, galhos submersos e variedade de plantas aquáticas, as quais, segundo Barbour et al. (1999) e Vlach et al. (2005), representam um ambiente com excelente complexidade do habitat, principalmente relacionada à alimentação e reprodução das espécies aquáticas. 
Silva (2010), estudando a influência da estrutura do habitat na assembleia de peixes do rio Cuiabá, constatou que o padrão de distribuição dessas assembleias dependeu totalmente da estrutura do leito. Além disso, o autor verificou que a composição das diferentes espécies foi totalmente distribuída entre os mais variados substratos, fato que pode ocorrer na bacia do rio de Ondas, localizada também no bioma Cerrado.

O leito é um componente multifatorial da análise estrutural do ambiente, que é influenciado por subparâmetros, como a textura, o grau de compactação, o tamanho das partículas presentes e a área superficial (Silveira, 2004), que podem, de maneira distinta, atuar na composição e abundância das espécies aquáticas, considerando suas adaptações.

Assim, considerando as diferentes preferências das espécies aquáticas relacionadas aos subparâmetros do leito e a diversidade particular de ambientes apresentada por cada trecho, não se pode afirmar com base nesse parâmetro que o trecho do baixo curso apresenta melhor disponibilidade de ambiente. Os dois trechos apresentaram diferentes características para ocorrência de uma fauna aquática diferenciada e diversificada.

\subsection{Disponibilidade de ambientes para os organismos aquáticos}

A complexidade da estrutura dos ambientes apresentada pelos dois trechos favorece a diversidade biológica da bacia do rio de Ondas, tendo em vista a disponibilidade de ambientes com diferentes características, que beneficiam as diversas aptidões das espécies aquáticas à estrutura física do canal.

Os trechos apresentaram diferenças nos parâmetros topobatimétricos, do leito e hidrodinâmicos, resultando em diferentes estruturas disponíveis, consequentemente, como previsto pela Teoria do Rio Continuum (Vannote et al., 1980), pode ocorrer também diferenças na diversidade de espécies, pelo fato do ambiente ser definidor dessa especificidade.

Condição semelhante à do rio de Ondas foi observada por Ferreira e Castro (2005), ao estudarem a estrutura dos ambientes de trechos do rio das Velhas, em Minas Gerais. Os autores confirmaram a influência das características físicas desses ambientes sobre a riqueza e abundância das comunidades aquáticas.

No trecho do alto curso, verificou-se como principais características formadoras do ambiente a predominância de leito arenoso, troncos submersos e macrófitas aquáticas. Além disso, é evidente a presença de margens escavadas, formando tocas que podem ser utilizadas para desova dos peixes. Pode-se constatar também, que há corredeiras e depressões, principalmente pela sinuosidade do canal, que favorecem a disponibilidade de ambiente (Fernandez, 2009).

Associada a tais fatores, e de maneira determinante e particular, o trecho do alto curso possui uma extensa mata de galeria inundável, que, com a elevação da vazão no período chuvoso, propicia o acúmulo da água proveniente do canal, disponibilizando ambiente diferenciado do verificado no período seco.

De maneira distinta, no trecho do baixo curso houve predominância de leito com material grosseiro, associado à elevada velocidade da corrente e baixa profundidade. Além disso, observa-se a disponibilidade de serapilheira para a comunidade aquática, e de diferentes ambientes, ocasionados pela variação nos diâmetros do material constituinte do leito, e deposições de areia em alguns pontos das margens, particularmente na margem esquerda.

No trecho do baixo curso, mesmo possuindo pouca oscilação quanto à inundação, por apresentar-se encaixado, ocorrem alterações na sua conformação física, pelo fato de vários matacões e pequenas ilhas vegetadas ficarem submersos durante o período de cheias, mudando temporariamente a configuração do canal. Mesmo com esta favorável heterogeneidade, pelo fato de estar localizado próximo ao centro urbano do município de Barreiras, esse trecho possui degradação em suas margens. 
Percebe-se, com as observações citadas, que o rio de Ondas apresenta características morfométricas diferenciadas entre os trechos do alto e baixo curso. No baixo curso há o predomínio de corredeiras e de materiais grosseiros, características esperadas de serem encontradas no alto curso, uma vez que os remansos e os materiais com diâmetros menores ocorrem predominantemente no baixo curso das bacias hidrográficas (Allan e Castillo, 2007; Rodrigues et al., 2010).

Conforme Riccomini et al. (2009), essas características estão associadas à estrutura geológica e geomorfológica das diversas regiões, sendo que a existência de rupturas nos declives causadas por falhas geológicas ou rochas ao longo dos rios podem formar ambientes de corredeiras e de cachoeiras.

\section{CONCLUSÕES}

As configurações físicas dos trechos do alto e baixo curso do rio de Ondas contribuem com diferentes ambientes disponíveis para a biota aquática, em particular os peixes, podendo resultar em distintas comunidades ícticas no alto e no baixo curso da bacia, mostrando a importância destes estudos no entendimento da estrutura dos ambientes e das comunidades aquáticas. Constatou-se ainda significante influência das características litológicas da região na geração da descontinuidade serial do rio, influenciando consequentemente nos processos ecológicos ocorrentes na bacia, relacionados principalmente à composição e distribuição da biota aquática.

\section{AGRADECIMENTOS}

À Fundação de Amparo à Pesquisa do Estado da Bahia - FAPESB (Termo de Outorga n $^{\circ}$ APP 0053/2011) e ao Conselho Nacional de Desenvolvimento Científico e Tecnológico CNPq (Processo n $472279 / 2013-0$ ), pelo apoio financeiro.

\section{REFERÊNCIAS}

ALlAN, J. D.; CASTILlO, M. M. Stream ecology: structure and function of running waters. New York: Springer, 2007.

ASSOCIAÇÃO BRASILEIRA DE NORMAS TÉCNICAS - ABNT. Nbr 7181/84: solo análise granulométrica. Rio de Janeiro, 1984.

ASSOCIAÇÃO BRASILEIRA DE NORMAS TÉCNICAS - ABNT. Nbr 6457/86: amostra de solo - preparação para ensaios de compactação e ensaios de caracterização. Rio de Janeiro, 1986.

BARBOUR, M. T.; GERRISTSEN, J.; SNYDER, B. D.; STRIBLING J. B. Rapid bioassessment protocols for use in streams and wadeable rivers: periphyton, benthic macroinvertebrates and fish. EPA 841-B-99-002. $2^{\text {nd }}$ Edition. Washington: USEPA, 1999.

BESCHTA, R. L.; PLATTS, W. S. Morphological features of small streams: significance and function. Water Resources Bulletin, v. 22, n. 3, p. 369-379, 1986. http://dx.doi.org/10.1111/j.1752-1688.1986.tb01891.x

BEZERRA-NETO, J. F.; PINTO-COELHO, R. M. New morphometric study of Lake Dom Helvécio, Parque Estadual do Rio Doce (PERD), Minas Gerais: utilization of advanced methodology for bathymetric mapping. Acta Limonologica Brasiliensia, v. 20, n. 2, p. 117-130, 2008. 
BOËCHAT, I. G.; PAIVA, A. B. M.; HILLE, S.; GÜCKER, B. Land-use effects on river habitat quality and sediment granulometry along a 4th-order tropical river. Revista Ambient. Água, v. 8 n. 3, p. 54-64, 2013. http://dx.doi.org/10.4136/ambi-agua.1232

CASTRO, K. B.; MARTINS, E. S.; GOMES, M. P.; REATTO, A.; LOPES, C. A.; PASSO, D. P. et al. Caracterização geomorfológica do município de Luís Eduardo Magalhães. Planaltina: EMBRAPA Cerrados, 2010.

CORTES, R. M. V.; FERREIRA M. T.; OLIVEIRA S. V. D.; HUGHES, S. J. Combining habitat and biological characterization: ecological validation of the river habitat survey. Limnetica, v. 27, n. 1, p. 39-56, 2008. http://dx.doi.org/10400.5/5142

CUNHA, S. B.; GUERRA, A. J. T. Geomorfologia: exercícios técnicas e aplicações. Rio de Janeiro: Bertrand Brasil, 2011.

DAMASCENO, O. S. Geomorfologia fluvial da bacia hidrográfica do rio de Ondas. Caminhos da Geografia, v. 12, n. 39, p. 126-136, 2011.

EMPRESA BRASILEIRA DE PESQUISA AGROPECUÁRIA - EMBRAPA. Manual de métodos de análises de solos. Rio de Janeiro: EMBRAPA Solos, 1997.

EMPRESA BRASILEIRA DE PESQUISA AGROPECUÁRIA - EMBRAPA. Sistema brasileiro de classificação de solos. Rio de Janeiro: EMBRAPA-SPI, 2009.

FANTIN-CRUZ, I.; LOVERDE-OLIVEIRA, S.; GIRARD, P. Caracterização morfométrica e suas implicações na limnologia de lagoas do Pantanal Norte. Acta Scientiarum. Biological Sciences, v. 30, n. 2, p. 133-140, 2008.

FERNANDEZ, O. V. Q. Discriminação de habitats aquáticos no córrego Guavirá, Marechal Cândido Rondon (PR). Revista Geografias, v. 5, n. 1, p. 22-36, 2009.

FERREIRA H. L. M.; CASTRO P. T. A. Ecomorphological analysis of fluvial habitats of the upstream part of Rio das Velhas/MG, Brazil. Sociedade \& Natureza, v. 1, n. 1, p. 327 $336,2005$.

GOLDSTEIN, R. M.; MEADOR, M. R.; RUHL, K. E. Relative influence of streamflows in assessing temporal variability in stream habitat. Journal of the American Water Resources Association, v. 43, n. 3, p. 642-650, 2007. http://dx.doi.org/10.1111/j.17521688.2007.00051.x

GOOGLE. Google Earth. Programa computacional, versão 7.1.1.1888. [S.1.]: Google Inc., 2013.

GORDON, N. D.; MCMAHON, T. A.; FINLAYSON, B. L.; GIPPEL, C. J.; NATHAN, R. J. Stream hydrology: an introduction for ecologists. West Sussex: John Wiley \& Sons, 2004.

GORMAN, O. T.; KAR, J. R. Habitat structure and stream fish communities. Ecology, v. 59, n. 3, p. 507-515, 1978. http://dx.doi.org/10.2307/1936581

HAWKINS, C. P.; KERSHNER, J. L.; BISSON, P. A.; BRYANT, M. D.; DECKER, L. M.; GREGORY, S. V. et al. A hierarchical approach to classifying stream habitat features. Fisheries, v. 18, n. 6, p. 3-12, 1993. http://dx.doi.org/10.1577/1548-8446(1993)018<0003:AHATCS>2.0.CO;2

INSTITUTO BRASILEIRO DE GEOGRAFIA E ESTATÍSTICA - IBGE. Manual do Usuário: posicionamento por ponto preciso. Rio de Janeiro, 2009. 
JOWETT, I. G. Method for objectively identifying pool, run, and riffle habitats from physical measurements. New Zealand Journal of Marine and Freshwater Research, v. 27, n. 2, p. 241-248, 1993. http://dx.org.br/10.1080/00288330.1993.9516563

KAUFMANN, V.; PINHEIRO, A. Relações entre diversidade íctia e fatores hidrodinâmicos de um riacho na bacia do rio Uruguai. Biota Neotropica, v. 9, n. 1, p. 47-53, 2009. http://dx.doi.org/10.1590/S1676-06032009000100006

KRUEGER, C. P.; VEIGA, L. A. K.; FAGGION, P. L. Levantamento batimétrico no rio Uruguai. In: CONGRESSO BRASILEIRO DE CARTOGRAFIA, 21., 2003, Belo Horizonte. Anais... Belo Horizonte: IBGE, 2003.

LEANDRO, G. R. S.; SOUZA, C. A. Pantanal de Cáceres: composição granulométrica dos sedimentos de fundo no rio Paraguai entre a foz do rio Cabaçal e a cidade de Cáceres, Mato Grosso, Brasil. Revista Ambiente \& Água, v. 7, n. 2, p. 263-276, 2012. http://dx.doi.org/10.4136/ambi-agua.876

LOWE-McCONNELL, R. H. Estudos ecológicos de comunidades de peixes tropicais. São Paulo: EDUSP, 1999.

MARSH-MATTHEWS, E.; MATTHEWS, W. J. Geographic, terrestrial and aquatic factors: which most influence the structure of stream fish assemblages in the midwestern United States? Ecology of Freshwater Fish, v. 9, n. 1-2, p. 9-21, 2000. http://dx.doi.org/10.1034/j.1600-0633.2000.90103.x

MARTINS, M. E.; HONDA, E. A. Caracterização hidráulica dos canais da bacia da Água da Cachoeira e do ribeirão do Alegre. In: VILAS BÔAS, O.; DURIGAN, G. Pesquisas em conservação e recuperação ambiental no oeste Paulista. São Paulo: Páginas e Letras, 2004.

MINATTI-FERREIRA, D. D.; BEAUMORD, A. C. Adequação de um protocolo de avaliação rápida de integridade ambiental para ecossistemas de rios e riachos: aspectos físicos. Revista Saúde e Ambiente, v. 7, n. 1, p. 39-47, 2006.

OLIVEIRA, E. D. Impactos da urbanização na geometria hidráulica de canais fluviais da bacia hidrográfica do rio Cascavel, Guarapuava/PR. 2011. 158 f. Dissertação (Mestrado em Geografia) - Universidade Estadual do Centro Oeste, Guarapuava, 2011.

QUEIROZ, F. L. L.; ROCHA, P. C. Avaliação de sedimentos do leito no canal Curutuba / planície fluvial do alto rio Paraná, Mato Grosso do Sul - Brasil. Revista AGB/TL, v. 7, n. 11, p. 147-164, 2010.

RESCK, R.; BEZERRA-NETO, J. F.; PINTO-COELHO, R. M. Nova batimetria e uma avaliação ecológica de parâmetros morfométricos da Lagoa da Pampulha (Belo Horizonte, Brasil). Revista Geografias, v. 3, n. 2, p. 13-23, 2007.

RICCOMINI, C.; ALMEIDA, R. P.; GIANNINI, P. C. F; MANCINI, F. Processos fluviais e lacustres e seus registros. In: TEIXEIRA, W. (Org.). Decifrando a terra. São Paulo: Companhia Editora Nacional, 2009.

RODRIGUES, A. S. L.; MALAFAIA, G.; CASTRO, P. T. A. A importância da avaliação do habitat no monitoramento da qualidade dos recursos hídricos: uma revisão. SaBios, v. 5, n. 1, p. 26-42, 2010. 
SILVA, S. E. Efeito do uso do solo e estrutura do habitat na assembleia de peixes de riachos da bacia do rio Cuiabá, MT. 2010. 105 f. Dissertação (Mestrado em Ecologia e Conservação da Biodiversidade) - Universidade Federal de Mato Grosso, Cuiabá, 2010.

SILVEIRA, M. P. Aplicação do biomonitoramento para avaliação da qualidade da água em rios. Jaguariúna: EMBRAPA Meio Ambiente, 2004.

SOARES NETO, J. P. Avaliação geoambiental da bacia do rio das Ondas no oeste da Bahia. 2005. 233 f. Tese (Doutorado em Geotecnia) - Universidade de Brasília, Brasília, 2005.

SOARES NETO, J. P.; SOUZA, N. M. Características fisiográficas da sub-bacia hidrográfica do rio das Ondas ao longo do tempo e suas relações ambientais. Magistra, Cruz das Almas - BA, v. 19, n. 2, p. 104-111, 2007.

SONTEK. Manual do sistema Riversurveyor S5/M9 versão 1.0. San Diego: YSI Incorporated, 2009.

SOUZA, C. E.; BARRELLA, W. Atributos ecomorfológicos de peixes do Sul do Estado de São Paulo. Revista Eletrônica de Biologia, v. 2, n. 1, p. 1-34, 2009.

TEJERINA-GARRO, F. L.; MÉRONA, B. Flow seasonality and fish assemblage in a tropical river, French Guiana, South America. Neotropical ichthyology, v. 8, n. 1, p. 145-154, 2010. http://dx.doi.org/10.1590/S1679-62252010005000005

TUPINAMBÁS, T. H.; CASTRO, D. M. P.; FRANÇA, J. S.; CALLISTO, M. Alterações de vazão em comunidades bentônicas: subsídio ecológico para parametrização de vazões ambientais. In: SIMPÓSIO BRASILEIRO DE RECURSOS HÍDRICOS, 19., 2011, Maceió. Anais... Maceió: ABRH, 2011. 1 CD-ROM.

VANNOTE, R. L.; MINSHALL, G. W.; CUMMINS, K. W.; SEDELL, J. R.; CUSHING, C. E. The river continuum concept. Canadian Journal of Fisheries and Aquatic Sciences, v. 37, n. 1, p. 130-137, 1980. http://dx.doi.org/10.1139/f80-017

VLACH, P.; DUŠEK, J.; ŠVÁTORA, M.; MORAVEC, P. Fish assemblage structure, habitat and microhabitat preference of five fish species in a small stream. Folia Zoologica, v. 54, n. 4, p. 421-431, 2005.

WARD, J. V.; STANFORD, J. A. The serial discontinuity concept in lotic ecosystems. In: FONTAINE, T. D.; BARTHELL, S. M. (Eds.). Dynamics of lotic ecosystems. Michigan: Ann Arbor Science, 1983.

WENTWORTH, C. K. A scale of grade and class terms for clastic sediments. The Journal of Geology, v. 30, n. 5, p. 377-392, 1922. 